\title{
Correlation Between Egg Weight and Egg Characteristics in Japanese Quail
}

\author{
Godson Aryee*, Gabriel Adu-Aboagye, Mark Ewusi Shiburah, Theresah Nkrumah, \\ David Amedorme
}

Council for Scientific and Industrial Research, Animal Research Institute, Accra, Ghana

Email address:

godsonaryee28@gmail.com (G. Aryee)

${ }^{*}$ Corresponding author

To cite this article:

Godson Aryee, Gabriel Adu-Aboagye, Mark Ewusi Shiburah, Theresah Nkrumah, David Amedorme. Correlation Between Egg Weight and Egg Characteristics in Japanese Quail. International Journal of Animal Science and Technology. Vol. 8, No. 3, 2020, pp. 51-54. doi: $10.11648 /$ j.avs.20200803.11

Received: February 7, 2020; Accepted: February 20, 2020; Published: June 8, 2020

\begin{abstract}
A study was undertaken to predict the correlation between egg weight and egg characteristics in quail. Data was collected on 102 eggs collected from female quails at 28 weeks. Eggs were numbered, weighed and classified into six egg weight groups: below 9.0g, 9.0-9.5g, 9.6-10.0g, 10.1-10.5g, 10.6-11.0g, and above 11g group. There were 17 eggs per egg weight group. Data was collected on egg weight, shell weight, shell ratio, albumen height, albumen weight, albumen ratio, albumen index, yolk height, yolk diameter, yolk weight, yolk ratio and Haugh Unit. Data collected were analysed using the General Linear Model (GLM) procedure of the Genstat edition 11. The correlation between the various characteristics of egg were determined. The result shows that Albumen diameter, albumen length and albumen width were influenced by size of egg $(p<0.05)$. Albumen diameter and albumen length increases with increasing egg size. There was a positive correlation between egg length and albumen (0.448), albumen diameter (0.463), shell surface area $(p<0.01)$. Egg width, height, shape index, shell ratio and shell surface area were significantly $(p>0.05)$ influenced by the sizes of quail eggs. The egg sizes of above $11 \mathrm{~g}$ had the best egg length followed by $10.6 \mathrm{~g}-11.0 \mathrm{~g}, 10.1 \mathrm{~g}-10.5 \mathrm{~g}, 9.6 \mathrm{~g}-10.5 \mathrm{~g}, 9.0 \mathrm{~g}-9.5 \mathrm{~g}$ and below $9.0 \mathrm{~g}$ had the least egg length indicating a direct relationship between egg length and egg weight. The positive correlations between the internal and external egg quality traits indicated that the traits can be improved through selection.
\end{abstract}

Keywords: Correlation, Haugh Unit, Albumen Diameter, Egg Quality, Shell Surface Area

\section{Introduction}

Quails are highly prolific with shorter generation interval, require less space, feed and capital to start with, have greater resistance to diseases and they can be reared under wide range of climate and farm conditions compared to other species of poultry. Breeding of quails become important because of their meat and eggs. Quails are worldly accepted due to the medicinal value of their meat and eggs. The quality of an egg influences the chick which indirectly influences the meat that is produced. Egg production is an important economic trait in poultry breeding that determines the efficiency of chick production for further rearing for meat It is influenced by several factors such as nutrition, management, environment etc. External egg quality traits such egg weight, shell weight, shell thickness as well as internal egg quality traits such as albumen and yolk characteristics are very important for the consumers and the egg product industry [1]. A research conducted by Narushin and Romanov [2] revealed that the egg quality traits of an egg is highly influenced by the genotype of the birds, breeding systems, management, nutrition and egg weight. Most poultry breeders and farmers consider weight of the egg very important in determining their choice of birds [3] as it can affect both egg quality and grading [4]. Egg weight is usually the total fraction of albumen, egg yolk and eggshell. Generally, the larger the egg, the larger the yolk and egg albumen and vice versa [5]. Iposu et al [5] reported negative correlations between egg weight and albumen height as well as egg weight and Haugh Unit. Additional conclusions were also reported by Sekeroglu and Altuntas [6] with positive 
correlations among egg weight and shape index, yolk width, yolk height and albumen index. Despite the current studies on internal and external egg characteristics and their correlation, the researches exploring those features in quails, including phenotypic correlation, remain very scant. Therefore, the objectives of the present study were to evaluate the influence of different egg weight groups on external and internal characteristics and also to determine the correlation among these traits of Japanese quail eggs.

\section{Materials and Methods}

\subsection{Quails and Dgg Collection}

The study took place at the Quails Unit of the CSIRAnimal Research Institute, Accra, Ghana, where 102 eggs were collected from female quails at 28 weeks old to be used as the experimental material and transported to the Biotechnology and Molecular Biology laboratory of the CSIR-Animal Research Institute, Accra, Ghana where conditions were optimized for accurate data measurement.

The birds were grouped into 50 each in a cage. Feed and water were given ad libitum. They were fed with commercial diet containing $20 \% \mathrm{CP}$ and $2,750 \mathrm{kcal}$ of $\mathrm{ME} / \mathrm{kg}$ from a feed company and received 24 hours of light per day. All quails were vaccinated against common diseases during the experimental period. A total number of 102 eggs were collected within 24 hours of lay for the study. Eggs were numbered, weighed and classified into six egg weight groups: below 9.0g, 9.0-9.5g, 9.6-10.0g, 10.1-10.5g, 10.6-11.0g, and above $11 \mathrm{~g}$ group. There were 17 eggs per egg weight group.

\subsection{Egg Measurements}

Eggs were weighed using an electronic scale with the accuracy of $0.01 \mathrm{~g}$. After breaking and separating egg components, eggshells were washed, air-dried and weighed. For internal egg quality characteristics, a caliper was used to measure the length and width of albumen and yolk.

In addition, parameters of indexes of albumen, yolk and $\mathrm{HU}$ were calculated as followed: Albumen index (\%) = (albumen height, $\mathrm{mm}$ /average of albumen length, $\mathrm{mm}$ and albumen width, mm) x 100; Yolk index $(\%)=$ (yolk height, $\mathrm{mm} /$ yolk diameter, mm) $\mathrm{x} 100$ and Haugh unit $=100 \mathrm{x}$ $\log (\mathrm{AH}+7.57-1.7 \times \mathrm{EW} 0.37)$, where $\mathrm{AH}=$ albumen height $(\mathrm{mm})$ and $\mathrm{EW}=$ egg weight $(\mathrm{g})[7,8]$.

\subsection{Statistical Analysis}

Data collected were analysed using the General Linear Model (GLM) procedure of the Genstat Edition 11 according to the following model: Yik $=\mu+\mathrm{Wi}+$ eik; where: Yik is the phenotypic value of the traits (egg weight, shell weight, shell ratio, albumen height, albumen weight, albumen ratio, albumen index, yolk height, yolk diameter, yolk weight, yolk ratio, and $\mathrm{HU}) ; \mu$ is the overall mean; $\mathrm{Wi}$ is the effect of the egg weight groups $(1,2,3,4,5,6)$; and eik is the random error. The differences and their significance among egg weight groups were done by using Turkey's test at $95 \%$ levels of Probability.

\section{Results and Discussion}

\subsection{Effects of Egg Size on Internal Egg Characteristics}

Albumen diameter, albumen length and albumen width were influenced by size of egg $(p<0.05)$. Albumen diameter and albumen length increases with increasing egg size. Eggs above $11 \mathrm{~g}$ had the widest albumen diameter and those eggs of size of $9.0 \mathrm{~g}$ had the least albumen diameter. Albumen height, Yolk index, Albumen index, Yolk diameter, and Yolk height were not significantly influenced by the size of eggs. There was a positive correlation between egg length and albumen (0.448), albumen diameter (0.463), shell surface area $(p<0.01)$. The significant and positive correlations indicated that the longer egg length had a positive effect on egg weight. Albumen length is highly correlated to egg length. This implies selection for egg length will automatically select for Albumen length. Egg width is positively correlated to albumen length. This indicates that improvement of albumen height, yolk height and yolk width will result in a better yolk index. Dependent on this result, egg freshness will be improved since yolk index determines egg freshness.

There was a highly significant negative correlation between yolk index and yolk diameter while a negative correlation between albumen index and albumen length was recorded. The physical qualities of quails' eggs play a very critical role in embryonic development. According to the finding of [9] Haugh unit was not influenced by egg size in quails. However, they reported of significant effect on larger eggs on yolk height, yolk diameter, yolk weight, albumen height and albumen weight than the small eggs.

Duman et al [10] reported significantly positive correlation between egg shape index and egg surface area. However, [11]reported non-significant correlation negative correlation shape index and egg surface area. However, egg weight has significant $(p<0.01)$ influence on shell ratio, unit surface shell weight $(p>0.05)$.

\subsection{Effects of Egg Size on External Egg Characteristics}

The result on the influence of egg size on external and internal egg characteristics is shown in table 1 above. Egg width, height, shape index, shell ratio and shell surface area were significantly $(p>0.05)$ influenced by the sizes of quail eggs.

The egg sizes of above $11 \mathrm{~g}$ had the best egg length followed by $10.6 \mathrm{~g}-11.0 \mathrm{~g}, 10.1 \mathrm{~g}-10.5 \mathrm{~g}, 9.6 \mathrm{~g}-10.5 \mathrm{~g}, 9.0 \mathrm{~g}-9.5 \mathrm{~g}$ and below $9.0 \mathrm{~g}$ had the least egg length indicating a direct relationship between egg length and egg weight. Higher egg weights correspond with higher egg length values. It further implies that, selection for better egg weight will automatically result in selection for egg length. Egg weight has a highly significant positive correlation with egg height (0.686) as shown in Table 2. This indicates that increases in egg weight will lead to increases in the length. From Table 1 
and 2 a similar result was obtained for the relationship between egg weight and width of the egg. Selection for better egg weight will invariably select eggs with better length and width.

Egg width and shell surface area were influenced by the weight of egg $(p<0.05)$. Egg width increases with increasing egg weight. There was a highly significant positive correlation between egg weight and egg width (0.730) and shell surface area (1.00). This may be due to the fact that egg yolk occupies the egg width area, thereby translating to heavier egg weight. Similar findings were reported by Monira et al [12] that egg weight significantly affect egg length and width. Also, the current result supports the report of [13]. These authors reported a correlation coefficient of 0.78 and 0.84 between egg weight with egg length and egg width, respectively. Based on the correlations, they concluded that egg length and egg width were better predictors of egg weight when compared to egg shape index.
The findings determined in this study are also in agreement with the reports of [14], they found highly significant correlations between the egg weight with egg length and egg width. Also, [15] reported significant correlations between egg weight with egg length and egg width.

However, shell ratio and unit surface shell weight were not significantly $(p>0.05)$ influenced by egg weight. The result further shows that there was positive-non-significant correlation between shell thickness and egg weight and egg width. The findings of current study differ from that of Nwagu et al. [16]; Obike and Azu [17] who reported of highly significant correlation between egg weight and egg width in chicken and Guinea fowl. There was non-significant negative correlation between egg weight and shape index (0.014).

Egg weight had no significant effect on Haugh unit, shape index, shell thickness and shell weight.

Table 1. Influence of Egg Weight on Internal and External Egg Characteristics.

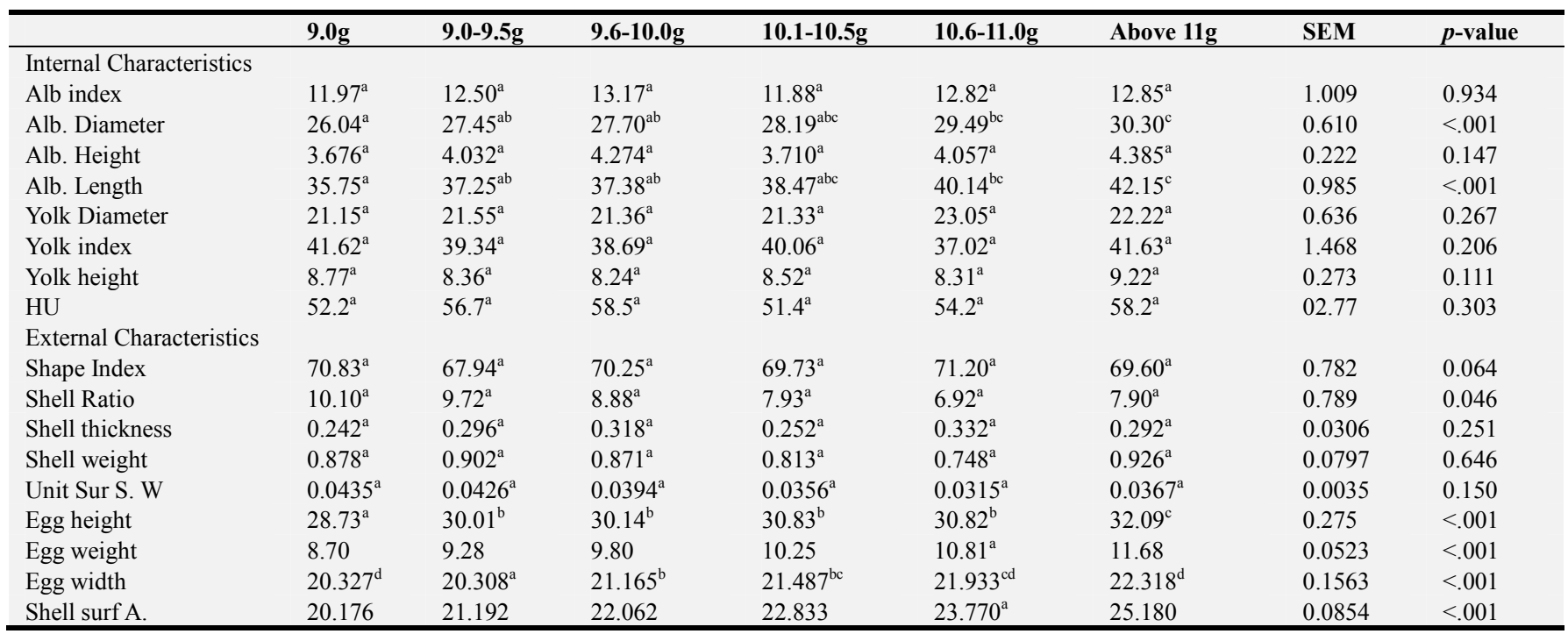

Table 2. Correlation Coefficients of Egg Characteristics.

\begin{tabular}{|c|c|c|c|c|c|c|c|c|c|c|c|c|c|c|c|c|}
\hline & EH & EW & ST & SW & AH & YH & YD & $\mathbf{A L}$ & AD & SI & SHA & USSW & SR & AI & YI & $\mathrm{HU}$ \\
\hline$\overline{\mathrm{EH}}$ & $.686^{* *}$ & $.730^{* *}$ & .138 & -.012 & .156 & .145 & .148 & $.448^{* *}$ & $.463^{* *}$ & -.014 & $1.000^{* *}$ & $-.213^{*}$ & $-.275^{* *}$ & .042 & .008 & .068 \\
\hline EW & & $.466^{* *}$ & .137 & .029 & 133 & .038 & $.174^{*}$ & $.414^{* *}$ & $.390^{* *}$ & $-.543^{* *}$ & $.687^{* *}$ & -.112 & -.155 & -.030 & -.100 & .089 \\
\hline ST & & & .060 & .130 & $.174^{*}$ & .121 & .149 & $.355^{* *}$ & $.382^{* *}$ & $.485^{* *}$ & $.733^{* *}$ & -.014 & -.060 & .062 & .002 & .028 \\
\hline SW & & & & -.066 & -.088 & -.078 & .024 & .048 & .127 & -.077 & .139 & -.097 & -.106 & -.160 & -.075 & -.102 \\
\hline $\mathrm{AH}$ & & & & & $-.209^{*}$ & .152 & .019 & .036 & -.120 & .102 & -.013 & $.977^{* *}$ & $.960^{* *}$ & $-.310^{* *}$ & .135 & $-.212^{*}$ \\
\hline YH & & & & & & .093 & -.078 & .142 & .109 & .035 & .154 & $-.227^{*}$ & $-.231^{* *}$ & $.749^{* *}$ & .083 & $.978^{* *}$ \\
\hline YD & & & & & & & .020 & .031 & -.074 & .057 & .143 & .121 & .111 & .014 & $.827^{* *}$ & .088 \\
\hline $\mathrm{AL}$ & & & & & & & & $.185^{*}$ & .135 & -.046 & .149 & -.021 & -.033 & -.150 & $-.505^{* *}$ & -.104 \\
\hline $\mathrm{AD}$ & & & & & & & & & $.638^{* *}$ & -.090 & $.449^{* *}$ & -.071 & -.104 & $-.254^{* *}$ & -.135 & .109 \\
\hline SI & & & & & & & & & & -.034 & $.462^{* *}$ & $-.226^{*}$ & $-.258^{* *}$ & $-.265^{* *}$ & $-.204^{*}$ & .067 \\
\hline SHA & & & & & & & & & & & -.012 & .110 & .112 & .091 & .094 & -.061 \\
\hline USSW & & & & & & & & & & & & $-.215^{*}$ & $-.276^{* *}$ & .041 & .006 & .065 \\
\hline SR & & & & & & & & & & & & & $.998^{* *}$ & $-.289^{* *}$ & .138 & $-.215^{*}$ \\
\hline AI & & & & & & & & & & & & & & $-.280^{* *}$ & .138 & $-.214^{*}$ \\
\hline YI & & & & & & & & & & & & & & & .090 & $.714^{* *}$ \\
\hline $\mathrm{HU}$ & & & & & & & & & & & & & & & & .093 \\
\hline
\end{tabular}

$\mathrm{EG}=$ egg height, $\mathrm{EW}=$ egg width, $\mathrm{ST}=$ Shell thickness, $\mathrm{SW}=$ Shell weight, $\mathrm{AH}=$ Albumen Height, $\mathrm{YH}=$ Yolk height, $\mathrm{YD}=$ Yolk diameter, $\mathrm{AL}=\mathrm{Albumen}$ length, $\mathrm{AD}=$ Albumen Diameter, SI=Shape Index, SHA=Shell Surface Area, USSW= Unit surface shell weight, SR=Shell Ratio, AI=Albumen Index, YI=Yolk Index, $\mathrm{HU}=$ Haugh Unit $* p<0.05 ; * * p<0.01$ 


\section{Conclusions}

The positive correlations between the internal and external egg quality traits indicate that the traits can be improved through selection.

\section{Acknowledgements}

We are grateful to all the members of the Quail Unit at the Katamanso station of Animal Research Institute, CSIR, Ghana for their assistance in collecting data for this study.

\section{Conflict of Interest}

The authors declare that they have no conflict of interest.

\section{References}

[1] Song K T, Choi S H and Oh H R. (2000). A comparison of egg quality of pheasant, chukar, quail and quinea fowl. Asian-Aust J Anim Sci. 13: 986-990.

[2] Narushin, V. G. And Romanov, M. N. (2002). Egg Physical Characteristics and Hatchability. World's Poultry Science Journal, 58: 297-303.

[3] Genchev, A. (2012). Quality and Composition of Japanese Quail Eggs (Coturnix japonica). Trakia Journal of Sciences, 10, 91-101.

[4] Farooq M, Mian MA, Ali M, Durrani FR, Asquar A and Muqarrab AK (2001). Egg traits of Fayomi bird under subtropical conditions. Sarad J Agric, 17: 141-145.

[5] Iposu, S. O., Onwuka, C. F. I. and Eruvbetine, D. (1994). The relationship between selected quality traits and egg size. Niger J Anim Prod; 21: 156-160.

[6] Sekeroglu, A. and Altuntas, E. (2009). Effects of egg weight on egg quality characteristics. J Sci Food Agric., 89: 379-383.

[7] Nasr, M. A. F., El-Tarabany, M. S. and Toscano. M. J. (2016). Effects of divergent selection for growth on egg quality traits in Japanese quail. Anim. Prod. Sci.; 56: 1797-1802.
[8] Sari, M., Serpil, I., Önk, K., Tilki, M. and Kırmızıbayrak, T. (2012). Effects of layer age and different plumage colors on external and internal egg quality characteristics in Japanese quails (Coturnix coturnix japonica). Arch. Geflügelk., 76 (4): 254-258.

[9] Hegab, I. and Hanaf, A. (2019). Effect of egg weight on external and internal qualities, physiological and hatching success of Japanese quail eggs (Coturnix japonica) Revista Brasileira de CiênciaAvícola; 10.1590/1806-9061-2018-0777.

[10] Duman, M., Şekeroğlu, A., Yıldırım, A., Eleroğlu, H. and Camc1, Ö. (2016). Relation between egg shape index and egg quality characteristics. European Poultry Science, 80.

[11] Alkan, S., Karsli, T., Galic, A. and Karabag, K. (2013). Determination of phenotypic correlations between internal and external quality traits of Guinea fowl eggs. KafkasUniv Vet FakDerg. 19: 861-867.

[12] Monira, K. N., Salahuddin, M. and Miah, G. (2003). Effect of breed and holding period on egg quality characteristics of chicken. Int. J Poult. Sci. 2: 261-263.

[13] Abanikannda, O. T. F., Olutogun, O., Leigh, A. O. and Ajayi, L. A. (2007). Statistical modelling of egg weight and egg dimension in commercial layers. Int. J Poult Sci. 6: 59-63.

[14] Tebesi, T., Madibela, O. R. and Moreki, J. C. (2012). Effect of storage time on internal and external characteristics of Guinea fowl (Numida meleagris) eggs. J Anim Sci Adv. 2: 534-542.

[15] Apuno, A. A., Mbap, S. T. and Ibrahim, T. (2011). Characterization of local chickens (Gallus gallus domesticus) in shelleng and song local government areas of Adamawa State, Nigeria. AgricBiol J N Am. 2: 6-14.

[16] Nwagu, B. I., Iyiola-Tunji, A. O., Akut, R. and Uhwesi, Y. A. (2010). Phenotypic correlation of egg quality traits of Anak and Hubbard broiler grandparent stock in the Northern Guinea Savanna. Proceedings of the 35th Annual Conference on Nigerian Society for Animal Production; March 14-17; Ibadan, Nigeria.

[17] Obike, O. M. and Azu, K. E. (2012). Phenotypic correlations among body weight, external and internal egg quality traits of pearl and black strains of Guinea fowl in a humid tropical environment. J AnimSci Adv. 2: 857-864. 